\title{
Awareness Towards Corona Virus Disease (COVID-19) and Its Prevention Methods in Selected Sites in Wolaita Zone, Southern Ethiopia: A Quick, Exploratory, Operational Assessment
}

This article was published in the following Dove Press journal:

Risk Management and Healthcare Policy

\author{
Eskinder Wolka' \\ Zewde Zema ${ }^{2}$ \\ Melkamu Worku ${ }^{3}$ \\ Kassahun Tafesse \\ Antehun Alemayehu Anjulo (D) ${ }^{4}$ \\ Kassahun Tekle Takiso ${ }^{5}$ \\ Hailu Chare (iD ${ }^{2}$ \\ Lolemo Kelbiso ${ }^{6}$ \\ 'Wolaita Sodo University College of Health \\ Sciences and Medicine, School of Public \\ Health, Sodo, Ethiopia; ${ }^{2}$ Wolaita Sodo \\ University College of Health Sciences and \\ Medicine, School of Pharmacy, Sodo, \\ Ethiopia; ${ }^{3}$ Wolaita Sodo University College \\ of Health Sciences and Medicine, School of \\ Midwifery, Sodo, Ethiopia; ${ }^{4}$ Wolaita Sodo \\ University College of Health Sciences and \\ Medicine, School of Medical Laboratory \\ Sciences, Sodo, Ethiopia; ${ }^{5}$ Wolaita Sodo \\ University College of Health Sciences and \\ Medicine, School of Medicine, Sodo, \\ Ethiopia; ${ }^{6}$ Wolaita Sodo University College \\ of Health Sciences and Medicine, School of \\ Nursing, Sodo, Ethiopia
}

Background: The novel corona virus disease 2019 (COVID-19) presents an important and urgent threat to global health and its effect is expected to get even worse in the middle- and lowincome countries where the health system is weak and fragile. Timely access to accurate information and public awareness on prevention methods is one of the feasible interventions in these countries. Identifying level of public awareness on disease prevention is important to mitigate the pandemic. The aim of this study was to explore the level of awareness and prevention methods of COVID-19 among residents in Wolaita Zone, Southern Ethiopia.

Methods: A qualitative study using a qualitative descriptive approach was conducted. Community members engaged in different service sectors were selected purposively. A total of 22 in-depth interviews were done. The transcripts were imported into OpenCode version 4.02 software packages. A qualitative thematic analysis approach was used to analyze the data.

Results: The findings revealed that $95.5 \%$ of the participants had heard about the disease COVID-19 and realized common modes of transmission. Some participants linked the disease with resentment of God on people or anger of God towards human kind. Importance of consuming hot drinks, ginger or garlic to prevent the disease was reported by participants. Negative attitude towards quarantine and isolation centers and stigmatizing people with a cough were documented in this assessment. Stigma and fear of isolation centers may prevent people from reporting the symptom of the disease and this can create favorable ground for the transmission. Challenges like problem of consistent availability of water supply, affordability of materials used to keep hygiene by rural poor, and keeping physical distancing in different public gathering places were reported.

Conclusion: Concerned bodies need to address gaps in public awareness by providing health education and continuous awareness creation.

Keywords: Awareness of COVID-19, Wolaita Zone, Southern Ethiopia

\section{Introduction}

The novel corona virus disease 2019 (COVID-19) is an infectious disease caused by a novel corona virus now called severe acute respiratory syndrome corona virus 2 (SARS-COV-2) and can be transmitted from person to person via contact with respiratory droplets. ${ }^{1}$ The novel corona virus disease 2019 (COVID-19) presents an important and urgent threat to global health. Since the outbreak in early December 2019 in the
Wolaita Sodo University College of Health Sciences and Medicine, School of Pharmacy, PO Box 138, Sodo, Ethiopia

Tel +251913271642

Fax +251465515216

Email zedzem@gmail.com
Risk Management and Healthcare Policy 2020:I3 230I-2308

submit your manuscrip

DovePress if in $>$ 
Hubei province of the People's Republic of China, the number of patients confirmed to have the disease and deaths from it increased at an alarming rate through time. ${ }^{1}$ It was initially reported to the World Health Organization (WHO) on December 31, 2019. On January 30, 2020, the WHO declared the COVID-19 outbreak a global health emergency. On March 11, 2020, the WHO declared COVID-19 a global pandemic. $^{2-4}$ Despite public health responses aimed at containing the disease and delaying the spread, several countries have been confronted with a critical care crisis, and more countries will almost certainly follow. ${ }^{4}$

Major prevention methods recommended by the WHO include; regularly and thoroughly clean hands with an alcohol-based hand rub or wash them with soap and water, maintaining social/physical distancing, avoid touching eyes, nose and mouth, and different protection measures based on the situations. ${ }^{5}$

It's very well known that the COVID-19 outbreak has placed unprecedented demands on the health systems of many countries around the globe. ${ }^{6}$ This is expected to get even worse in the middle- and low-income countries where the health system is weak and fragile. In countries that are hardest hit, health facilities and workforce are currently swamped by activities related to controlling the pandemic. $^{6}$

As a step for the preparation to respond to the COVID19 pandemic, African countries have established a Taskforce for Corona virus Preparedness and Response (AFTCON) that works in tandem with the African Union Commission, Africa Centers for Disease Control and Prevention. In line with this and as a member state of the African Union, Ethiopian's preparedness and the health system's capacity to respond to the COVID-19 is no exception. $^{7}$

Ethiopia reported the first case of COVID-19 on March 13, 2020. The trend shows a dramatic increase in the number cases with more indications of transmission in the community especially in the capital, Addis Ababa. In Ethiopia, four months after the announcement of the first case, 7560 COVID-19 cases had been identified by 13 July 2020. While the number of cases that recovered from the disease was $32 \%$ (2430), the number of people who died due to COVID-19 was 127 (case fatality rate of 1.679 deaths per 100 cases. The government of Ethiopia has taken several measures such as shutting down of schools including universities, restricting the movement of people under a State of Emergency (stay at home), introducing chains of training programs for health workers, identifying isolation areas and hospitalization sites, starting screening tests at Bole International Airport and different engagement in mobilizing resources including equipment, supplies, food, money and educating the people about the disease and preventive methods, and so on. ${ }^{8}$

In this COVID-19 pandemic, in addition to other interventions, timely access to accurate information and public awareness on prevention methods can be the difference between life and death. The stakes are high in developing countries like Ethiopia where millions of people have limited access to information because of low media access, insufficient internet penetration, illiteracy, and so on. ${ }^{8}$ In this pandemic, when everyone should be aware of the risks posed by COVID-19 and, most importantly, be informed about how to protect themselves and their families and societies at large. Currently, as part of a national effort, Wolaita Sodo University has been engaged in different intervention packages concerning the response to the COVID-19 pandemic. One of the activities is public education and information dissemination by using local media and other methods. But little is known about level of public awareness of the disease and its prevention methods. So, this assessment generates important information regarding the level of public awareness of the disease which in turn contributes to designing better mitigation strategies. Hence this study was conducted to explore the level of awareness and prevention methods of COVID-19 among Residents of Wolaita Zone, Southern Ethiopia.

\section{Methods}

The assessment was conducted in selected districts (Woredas) of Wolaita Zone, Southern Ethiopia. Residents from Damot Gale, Boloso Sore and Humbo areas were included in this study. A qualitative study with a descriptive qualitative approach was used. This method is a naturalistic inquiry and it is the method of choice for this assessment since straight description of an event or phenomenon is needed. Community members engaged in the transport service, shopping, market places, hotels and cafeterias, governmental and non-governmental organizations and religious organizations were selected purposively. Maximum variation sampling was used. Maximum variation sampling is a type of purposive sampling by which the participants view on a specific topic amongst different types of groups will be explored. A total of 22 study participants, who were engaged in different service sectors in selected assessment areas, were 
included. The service areas addressed in the assessment were; civil servants (4), traditional coffee (Jebena Buna) (2), religious leaders (3), motorbike drivers (4), trade in market areas (3), hotels (2), barbers (2) and shops/supermarkets (2).

In-depth interview (IDI) was chosen as the data collection method to capture awareness and practices related to COVID-19 by using an interview guide. The interview guide mainly includes, brief socio-demographic characteristics, awareness and prevention methods of COVID-19 and possible suggestions to tackle the pandemic. This method is useful to have as each participant has an opportunity to share feelings, perspectives, and experiences concerning the problem. A semi-structured interview guide which included socio-demographic components, awareness and prevention aspects of COVID-19 was used to collect data. Data collectors were health professionals with past experience and oriented on the study overview, objectives, participant selection, tool review and interview approach. The interview was audio-recorded by using a recorder. Interview data were reviewed periodically during data collection until data saturation ${ }^{9}$ was reached, according to the judgment of the research team.

Audio records were transcribed and translated into English and imported in to OpenCode version 4.02. A qualitative thematic approach was used to analyze the data. Data coding was done in each category by using the software. Once coding was complete, a code report was produced for each code, cleaned and prepared for synthesis. During synthesis and write up, meaning units were identified in relation to the aim of the study. Emerging meaning units that were extracted from each topic of the analysis were coded and then combined together to form categories, depending on their differences and similarities.

Potentially eligible and interested participants received consent forms in their local language and were informed that their participation would be voluntary and there would be no personal consequences or benefits to participation. Informed written consent was obtained from all participants. Confidentiality and anonymity was maintained when quoting research participants and the participants confirmed their agreement on publishing their anonymised quotes. This study complied with the Declaration of Helsinki. Written informed consent was obtained from the participants and a declaration of signed consent include the statement:

I have read or had read to me the information sheet that explains the reasons for the study, and all about the group discussion that I am being asked to participate in, all the questions I had about the study have been answered. I clearly understand what is being asked of me if I agree to participate in this study. I also know that I have the right to leave the study at any time if I do not want to continue. I am aware that all the information that I give will be kept confidential. I agree and confirm my agreement on publishing anonymized quotes and take part in this study and I put my signature.

This study was reviewed and approved by the Research Ethics Committee of the College of Health Sciences and Medicine, Wolaita Sodo University, Ethiopia. Letters of support were secured by the research team from all institutions and offices where data were collected.

\section{Results}

Major thematic areas considered during analysis were awareness towards the disease, prevention methods and challenges and suggestions to mitigate the pandemic in local context and presented as follows.

\section{Background Profile of Participants of IDIs} Most of the participants, 18 (81.8\%), included in this study were males and the mean age of the service providers is 27 years old (Table 1).

\section{Awareness on COVID-19}

Participants of IDIs were asked, regarding the disease COVID-19, about its cause and common symptoms. Accordingly, 18 of 22 participants indicated that COVID19 is a new disease which happened recently, affecting all people in all countries in the world, transmitted from person to person and caused by virus. Participants obtained information about the disease from different sources; common sources of information mentioned by the participants include; radio, television, social media, health care workers, telecom messages during outgoing call, religious leaders and friends/neighbors. Four of the participants linked the disease with resentment of God on people and some others had a confusion with the term zoonotic disease.

One of the participants who is barber explained the disease as follows;

As I heard from media, radio, TV, religious institutions and mobile health educators, it is a virus which is deadly and has no treatment that transmits from person to person through breathing or by air during coughing. It is affecting 
Table I Background Profile of Study Participants in Wolaita Zone, Southern Ethiopia, 2020

\begin{tabular}{|c|c|c|c|c|c|}
\hline Site & Ser. No & Age & Sex & Educational Status & Service Sector \\
\hline \multirow[t]{8}{*}{ Boloso Sore/Areka } & I & 31 & $M$ & Bachelor & Civil Servant \\
\hline & 2 & 20 & $\mathrm{~F}$ & Grade 7 & "Jebena Buna" \\
\hline & 3 & 24 & $M$ & Grade 10 & Motorbike driver \\
\hline & 4 & 23 & $M$ & Grade 12 & Merchant \\
\hline & 5 & 18 & $M$ & Grade 8 & Moto bike driver \\
\hline & 6 & 20 & $\mathrm{~F}$ & Grade 7 & "Jebena Buna" \\
\hline & 7 & 26 & $M$ & Level 4 & Civil Servant \\
\hline & 8 & 25 & M & Grade 10 & Barber \\
\hline \multirow[t]{10}{*}{ Humbo/Tebela } & 9 & 25 & $M$ & Grade 6 & Hotel worker \\
\hline & 10 & 22 & $M$ & Grade 10 & Motorbike driver \\
\hline & 11 & 31 & $M$ & Level 3 & Barber \\
\hline & 12 & 32 & M & Grade 12 & Merchant \\
\hline & 13 & 28 & $M$ & Grade 8 & Bajaj driver \\
\hline & 14 & 28 & $M$ & Grade 10 & Merchant \\
\hline & 15 & 29 & $\mathrm{~F}$ & MSC & Civil Servant \\
\hline & 16 & 52 & $M$ & MSC & Religious leader \\
\hline & 17 & 31 & $M$ & Grade 12 & Religious leader \\
\hline & 18 & 32 & $\mathrm{~F}$ & Diploma & Shop \\
\hline \multirow[t]{4}{*}{ Damot Gale/Boditi } & 19 & 30 & $M$ & Grade 10 & Hotel worker \\
\hline & 20 & 25 & $M$ & Bachelor & Supermarket \\
\hline & 21 & 34 & $M$ & Bachelor & Civil Servant \\
\hline & 22 & 26 & $M$ & Diploma & Religious leader \\
\hline
\end{tabular}

all people in all countries in the world.(Male participant, aged 31)

Another participant from another area, who is engaged in hotel management service said;

I heard the information from media and people talking about a disease called corona virus which I have not ever heard. I know that there is no detected case in our area but based on the information from media, cases are detected in other countries and Addis Ababa only in our country. Since then, I am practicing the messages told by health professionals for prevention from the disease acquisition. (Male participant, aged 30)

Two of the participants noted that the disease is the result of the anger of God since people do not obey the rule of God and one of the participants who is a "bajaj" driver explained that;

what I know is, it is the disease that came from God as result of our bad and evil acts, it has no drug to treat and the only option is pray to God to be protected from this type of disease. (Male participant, aged 28)

Another participant from another site similarly noted that the disease emerged by the order of God and he shared the above idea by saying;
I believe that, corona virus disease came from God because of our sin and we should pray to alleviate the problem and we should try to fight it by using all possible methods. (Male participant, aged 21)

A participant from a similar Woreda emphasized to follow all the instructions from the government despite his strong belief in God for the reason of the emergence of the disease as well as solutions for it and noted the situation as follows;

I recommend all people should kneel down for repentance. So far there are many evil acts we did, disobedience, homosexuality, genocide, ethnic targeted displacement, corruption, robbery and so many unethical acts. So, we have to ask forgiveness of God along with precautions from government. (Male participant, aged 52)

One of the participants, who is civil servant in his occupation, said that "it is confusing for me whether this disease can be transmitted from animal to human through eating animal products like raw meat since there are recommendations that avoid consuming raw meat." This idea was shared by another participant from another Woreda and he pinpointed the situation as follows; 
" ... the disease can be transmitted via raw meat consumption so I think there is a possibility of acquiring it from animals" (male participant, aged 28),

\section{Awareness of Symptoms of the Disease and Modes of Transmission}

Participants of the assessment were asked to reflect their opinion on common symptoms and modes of transmission of COVID-19; accordingly they forwarded their perspectives on symptoms of the disease and modes of transmission. Cough, fever, sneezing, diarrhea, throat pain, difficulty breathing and head ache were common symptoms of the disease mentioned by several participants. Based on the review of transcripts, participants indicated different modes of transmission of COVID-19, namely; hand shaking, hugging, sitting together, contact with droplets during coughing and sneezing, making contact with infected air and objects, skin penetration, and sharing clothes.

Concerning modes of transmission, one of the participants said;

The virus can be transmitted through contact, sneezing droplets, when we are sharing clothes with others, hand shaking, when we talking there are small droplets they may transmit disease, when we are close each other or sit together. These are the ways of transmissions. (Female participant, aged 29)

Droplet inhalation and contact with the droplet was pinpointed by another participant and he said;

Corona virus is a disease that can be transmitted from person to person via contact and also individuals might contract this virus through droplet inhalation. In addition to this, if a person touch different materials that might have come in touch with the virus, it favors the virus transmission in the developed countries and now a days, has also been health problem in Ethiopia. (Male participant, aged 24)

Based on the transcripts of interviews, some participants emphasized that the virus can be transmitted via skin penetration after hand shaking or making contact with an infected person. A bajaj driver from one of study Woredas said;

If we don't wash our hands, the virus can enter our body through penetration of skin of our hands. (Male participant, aged 18)
The above concern was shared by another participant from the same town and he further elaborated the issue as follows;

$\ldots$ at the time of hand shaking with the infected individual, uninfected individual can easily acquire the virus and at the same time it enters in to the body by penetrating hand, because it is very dangerous virus. (Male participant, aged 23)

\section{Prevention Methods}

Hand washing, avoiding hand shaking, wearing masks and gloves, using sanitizer, physical distancing, general personal hygiene, holy water, consuming hot drinks, chili papers, garlic and ginger were identified as prevention methods of the disease by participants of in-depth interview. According to the in-depth interview participants, hygiene was described in different ways namely; washing hands every 15 minutes, taking showers five times per week, washing hands three times per day and using sanitizer, soap and water together. Two participants assumed the fever screening as a final technique that declares their status and feel a sense of security. Negative perception towards quarantine and isolation center was indicated by some of the participants. The following quotes describe different views as follows;

As health professionals have been telling us washing hands every 15 minutes, rubbing with alcohol, avoid hand shaking, making physical distance at least 2 meter. (Male participant, aged 28)

To prevent disease, keeping social distancing, we have been practicing social distancing in funeral areas yesterday as well as the day before yesterday. There were professionals coordinating this. Another is minimizing social life. Very important way is washing hand frequently. Using masks, wearing gloves in the office is important since we are collecting revenues. Avoiding hand shaking is another method. (Female participant, aged 29)

A religious leader has briefed the importance of holy water to prevent the disease together with other precautions and he said;

We make members to sit far apart, we order them to wash their hands and they use holy water without sharing drinking materials and I believe this is helpful to prevent the disease. (Religious leader, male, aged 31) 
Based on a participant response, hot drinks and homemade prevention options were key to prevent COVID-19. She described by her own word as follows;

... this disease has come from foreign countries, we are ordered to pray God in churches, in addition we are using spices and herbs like garlic, ginger, chili papers and hot drinks which are important to prevent this infection. (Female participant, aged 20)

Based on the explanation of a participant, one time screening was considered as an adequate method to prevent the disease and he explained the issue as follows;

... I don't know about it in detail but to prevent the disease as it has no drug, for myself I got tested for the disease while I was coming from Shashemene, as I knew my status there is no problem but I want to teach others to get tested for the disease. (Male participant, aged 25)

A participant described how they changed their usual office set up and trend in order to prevent the disease, she explained the situation as follows;

In our office, our work has forces us to have frequent interaction with the people since we are collecting revenues. Another thing that poses risk is money that we are collecting. We can't lock the job; because the revenue and tax that we collect is necessary for salary and other payments. With us there is finger print machine. Since many people are touching it may transmit the disease. Therefore we clean machine with alcohol after everyone is recording finger print and we are making the customers who use machine to rub their hands with alcohol. Another is; we have hand washing corner at the gate. Therefore everyone washes his/her hand before getting in to office. We serve the customer through window. We don't allow them to enter to the rooms. (Female participant, aged 29)

\section{Challenges and Suggestions by Participants}

Participants noted challenges like consistent availability of water, affordability of materials used to keep hygiene for the rural poor, keeping physical distancing in funeral area and markets, lack of awareness (particularly in rural areas), difficulty of avoiding usual trend of greetings like hand shaking in rural areas, not obeying rules and instructions, misunderstanding on lifting of some of the restrictions like allowing motorbike movement, stigmatizing people with cough.

In this study, the participants were also asked for any comments and suggestions on the ways of preventing the pandemic by overcoming the challenges and minimizing its burden. The major suggestions forwarded by the participants include; continuous awareness creation, law enforcement and providing support for poor people. The following quotes describe different views and suggestions as follows;

Still people are shaking hands each other in rural area, for example today it is market day, if someone caught by the disease, disease my spread to everyone. People salute each other while selling animals. They kiss each other's hand, to show their agreement for selling. Therefore, it is good to teach the community continuously. (Male participant, aged 38)

It is difficult to prevent this disease in our area. For example motorbikes carries two or more customers at a time, they do not respect the rule. At rural area; people have no awareness about the disease. They don't know even as the disease is killer. Therefore, there should be intense teaching. Still there is gathering, sitting together. There should be continuous teaching. (Male participant, aged 32)

There is shortage of soap; food ingredients are expensive and not affordable for poor people. Therefore, government should try to provide the supplies to the poor either as donation or by affordable price. (Female participant, aged 29)

Government should force the community. For instance; motor vehicle ordered to use by maximum of two persons at a time. But they not obey this. Bajaj's do not obey too. Therefore they should be forced to obey the rule. Care should be taken in market areas and other gathering areas too. This is all that I can say. (Male participant, aged 45)

... as I saw a great gap from both the government and the people. For example: Majority of our people lives in the rural area but they have very little information about the disease so the government must address every kebele and each home. In addition to that as you know a lot of people are very poor and they obtain their expense from day to day activity so the government must support those in need. (Male participant, aged 23)

Sometimes peoples are not happy when you ignore hand shaking, they became emotional and respond aggressively. Most of the time they said you didn't believe in God that is why you develop fear for the disease he protects us. so, this need attention. On the other hand, there is no enough water for hand washing in every part of the city it is limited to some special areas that may contribute for the spread of the disease. (Male participant, aged 25) 
The most important thing that must need attention was people living in the rural area because there is no or little information about the virus because they lack mass media but majority of people are there, so the government must address this problem. In addition to this almost all the materials needed for protective purpose are in a very small amount or not at all. Please as you said you are coming from university please try to solve this scarcity. (Female participant, aged 23)

\section{Discussion on Key Findings}

This quick assessment aimed to explore the level of awareness and prevention methods of COVID-19 among residents of Wolaita Zone, Southern Ethiopia. The participants were civil servants, religious leaders, motorbike/bajaj drivers, merchants, hotel/café workers, barbers and people working in shops/supermarkets. The findings revealed that almost all of the participants heard about the disease COVID-19 and based on their expression it is viral disease affecting everybody in all countries in the world and transmitted from person to person.

Some participants linked the disease with resentment of God on people and they strongly believe in praying to God to be protected from the disease. The implication of this finding is, it is still essential to provide necessary education for the community in order not to neglect all necessary prevention methods of the disease while praying to God which is well recognized by Ethiopian government and currently it is included in the national television broadcasting program.

Some others had confusion with whether the disease is transmitted from animal to human because of advice like avoiding raw meat and other raw products. This shows the need for detail while educating people about the disease.

Findings from this assessment showed that most participants realized common modes of transmission of the disease, like contact with droplets during coughing and sneezing, making contact with infected air and objects via hands and so on, but some participants considered that the disease can be transmitted via skin penetration and this is also an important area that should be addressed during the education program.

The assessment reveals that most participants got information from different sources and they had awareness of common symptoms of COVID-19. The findings showed several participants mentioned methods of prevention of the disease as per the recommendations by the World Health Organization (WHO) but some of the participants rely on consuming hot drinks, ginger or garlic to prevent the disease and giving them a sense of security, and this needs a precaution since these things are not scientifically proven prevention methods for COVID-19 so far.

In addition, issues like negative attitudes towards quarantine and isolation centers, stigmatizing people with a cough, considering screening by measuring temperature as a final result of their COVID-19 status were documented in this assessment. So, it is helpful to consider these points during awareness creation and health education to mitigate the pandemic since issues like stigma and fear of isolation centers may prevent people from reporting the symptoms of the disease and this can create favorable grounds for the transmission.

To ensure credibility of the findings in this study, data collectors who are very familiar with the study area were selected and trained. Dependability refers to whether the findings of this study may be repeated in other places by other researchers and the study tools are available on request for others to do, consistently. Transferability is the term used to refer to the external validity in qualitative studies, the study addressed different areas of the Zone and service sectors and the finding is applicable in similar socio-cultural settings.

This assessment has some limitations. Although the study sites were drawn from 3 different Districts of the Wolaita Zone, the relative numbers of recruitment locations within these Districts were few and not necessarily representative of the entire rural community. The overall number of respondents, though limited by available resources and time, was in line with similar qualitative quick assessments of this type.

\section{Conclusion and Recommendations Conclusion}

Generally, most of the interviewed participants indicated that COVID-19 is a newly emerged viral disease, affecting all people in all countries in the world, transmitted from person to person. Some participants linked the disease with the anger of God on people and some others had confusion with zoonotic diseases.

Most participants mentioned common symptoms of the disease. Participants indicated different modes of transmission of COVID-19, explicitly; hand shaking, hugging, sitting together, contact with droplets during coughing and sneezing, making contact with infected air and objects, skin penetration, and sharing clothes.

Hand washing, avoiding hand shaking, wearing masks and gloves, using sanitizer, physical distancing, general 
personal hygiene, holy water, consuming hot drinks, chili papers, garlic and ginger were identified as prevention methods of the disease by participants of the in-depth interview.

Some participants assumed that screening by measuring temperature as a final technique that declares their status and felt a sense of security. Negative perception towards quarantine and isolation centers was indicated by some of the participants.

Participants noted challenges like problems of consistent availability of water, affordability of materials used to keep hygienic by the rural poor, keeping physical distancing in funeral areas and markets, lack of awareness (particularly in rural areas), difficulty in avoiding the usual trend of greetings like hand shaking in rural areas, not obeying rules and instructions, misunderstanding on lifting of some of the restrictions like allowing motorbike movement and stigmatizing people with a cough.

\section{Recommendations}

It is recommended to provide continuous awareness creation, community mobilization and strong law enforcement in some areas, like the transport sector. A local COVID-19 prevention taskforce should regularly attend events like funerals and markets to facilitate physical/social distancing (this may include health care workers, religious leaders, community leaders, security and so on).

\section{Acknowledgments}

We would like to acknowledge the zonal health department and local administrations, without whose cooperation this assessment would have been impossible. Study participants deserve special acknowledgment for all their cooperation in the data collection process and for providing genuine information that resulted in the accomplishment of this assessment.

\section{Disclosure}

The authors report no conflicts of interest for this work.

\section{References}

1. CDC. 2019 Novel Coronavirus, Wuhan, China. CDC; 2020. Available at https://www.cdc.gov/coronavirus/2019-ncov/about/index.html. Accessed January 27, 2020.

2. Gallegos A. WHO Declares Public Health Emergency for Novel Coronavirus. Medscape Medical News; 2020. Available athttps:// www.medscape.com/viewarticle/924596. Accessed January 31, 2020.

3. Ramzy A, McNeil DG; W.H.O. Declares Global Emergency as Wuhan Coronavirus Spreads:The New York Times. Available at: https://nyti. ms/2RER70M. 2020. Accessed: January 30, 2020.

4. The New York Times. Coronavirus Live Updates: W.H.O. Declares Pandemic as Number of Infected Countries Grows. The New York Times; 2020. Available at https://www.nytimes.com/2020/03/11/world/ coronavirus-news.html\#link-682e5b06. Accessed March 11, 2020.

5. Corona Virus Disease 2019 (COVID- 19), WHO advice for the public, 2020.

6. Lazzerini M, Putoto G. Lancet Glob Health 2020. Lancet Global Health. 2020;8(5):641. doi:10.1016/S2214-109X(20)30110-8

7. Kaba M, Kitaw Y. Novel coronavirus (2019-nCove) Reminiscent of Spanish flu: A Challenge to Global public health systems (Editorial). $J$ Health Dev. 2020;34:1.

8. Federal Democratic Republic of Ethiopia, Ministry of Health. Updated on Corona Virus Disease-2019 (COVID-19); 2020.

9. Morse JM. The significance of saturation. Qual Health Res. 1995;5 (2):147-149. doi:10.1177/104973239500500201.
Risk Management and Healthcare Policy

\section{Publish your work in this journal}

Risk Management and Healthcare Policy is an international, peerreviewed, open access journal focusing on all aspects of public health, policy, and preventative measures to promote good health and improve morbidity and mortality in the population. The journal welcomes submitted papers covering original research, basic science, clinical \& epidemiological studies, reviews and evaluations, guidelines, expert opinion and commentary, case reports and extended reports. The manuscript management system is completely online and includes a very quick and fair peer-review system, which is all easy to use. Visit http://www.dovepress.com/testimonials.php to read real quotes from published authors. 